\title{
Trends in Opioid Death Rates Following Implementation of Nevada's Opioid Prescribing Laws
}

\author{
Taylor Cornwell-Hinrichs, Cara Wyant, Cheryl Vanier, Weldon Havins, Joseph Paul Hardy
}

College of Osteopathic Medicine, Touro University Nevada, Henderson, The United States

Email address:

tcornwel@student.touro.edu (T. Cornwell-Hinrichs)

\section{To cite this article:}

Taylor Cornwell-Hinrichs, Cara Wyant, Cheryl Vanier, Weldon Havins, Joseph Paul Hardy. Trends in Opioid Death Rates Following Implementation of Nevada's Opioid Prescribing Laws. American Journal of Internal Medicine. Vol. 9, No. 4, 2021, pp. $204-209$. doi: 10.11648/j.ajim.20210904.17

Received: July 19, 2021; Accepted: July 29, 2021; Published: August 4, 2021

\begin{abstract}
In response to a rising opioid overdose epidemic, Nevada passed legislative bills SB 459, AB 474, and AB 239 between 2015 and 2019 to reduce opioid prescriptions and, in turn, opioid-related deaths in Nevada. This paper analyzes trends in opioid prescription rates relative to legal and illegal opioid death rates from June 2015 to May 2020 in Clark and Washoe Counties. Data on opioid prescriptions was obtained from the Nevada Board of Pharmacy. Data on all opioid-related deaths was obtained from the Clark County Office of the Coroner/Medical Examiner and the Washoe County Regional Medical Examiner. Clark County and Washoe County showed similar trends $(P=0.07)$, where AB 474 was associated with a $27.4 \%$ overall drop in prescription rates (from 68 per 1,000 people to 50 per 1,000), and it set up a trend of declining opioid prescribing rates that continued through May 2020. Prescription opioid death rates declined with prescription rates over time $(P<0.01)$, but illicit opioid deaths rose slightly (heroin) or dramatically (fentanyl) during the same period, with a particularly notable increase during the COVID-19 Stay at Home order. In conclusion, the goal of Nevada's three opioid prescription bills was to reduce the rate of Nevadans dying from opioid overdoses, yet more Nevadans are dying from opioids now than before the bills passed. We recommend three provisions to help balance appropriate accessibility to pain management for patients with the need to limit prescription opioid deaths: (1) Base law requirements on guidelines provided by professional or governmental agencies that are medically oriented, (2) Discipline first with education, then with sanctions, and (3) Enforce requirements through an entity which is very familiar with the providers' scope of practice, such as the Nevada State Board of Medical Examiners.
\end{abstract}

Keywords: Opioids, Opioid Related Deaths, Legislation, Nevada, SB 459, AB 474, AB 239

\section{Introduction}

People have benefited from the powerful therapeutic effects of the opium plant, Papaver somniferum, as far back as the 2,000 BCE Sumerian civilization [1]. In the 17th Century, English physician Thomas Sydenham formulated a tincture of opium and ethanol he called laudanum in order to anesthetize patients for surgery [1]. In the 19th Century, German pharmacist Friedrich Sertürner successfully purified the active ingredient of opium into a sleep aid and analgesic he called morphium, better known today as morphine [1]. Later in the 19th Century, an English chemist Charles Wright attempted to make a less-addictive form of morphine by acetylating it into diamorphine, which we now call heroin [2].

While opioids have long been an important tool in the physician's arsenal to combat moderate to severe pain, they can be addictive. The release of the synthetic opioid OxyContin (generic: oxycodone) by Purdue Pharma in 1996, hailed as a medical breakthrough for its long-lasting pain relief [1], was quickly followed by an increase in synthetic opioid deaths [3]. Although illicit opioids (i.e. heroin and fentanyl) were available, legally obtained opioids were the main cause of opioid-related deaths throughout the 1990s and early 2000s [3], and the problem continues. In 2018 alone, an estimated 67,367 people died from legal opioid prescriptions [3]. The misuse of synthetic opioids and subsequent overdose deaths has risen to such an extent in the US that it is now widely regarded as an epidemic. Today, roughly 120 people die each day from opioid-related drug overdose in the United States [4]. In Nevada alone, opioid related deaths increased $26 \%$ in 
four years: from 545 per 100,000 in 2014 to 688 deaths per 100,000 in 2018 [3]. In 2016, approximately 2.5 million opioid prescriptions were written in Nevada, which is the equivalent of 1 opioid prescription per person in Clark County [5].

In addition to loss of life, the opioid epidemic has intensified the burden on Emergency Departments across the state. From 2009-2017, the number of individuals with opioid-associated ED visits in Nevada increased 3\% [6]. The most recent Nevada overdose report for April 2021 states there has been a $21 \%$ decrease in opioid prescriptions over the last month, yet opioid-related ED visits in Nevada continue to climb [7]. While the majority of deaths are adults, it should also be noted that from 2005-2015 the prevalence of illicit opioid use in individuals 12-17 years old jumped $13.3 \%$ [8]. Clearly, the opioid crisis in Nevada is reaching a fever pitch.

In response to Nevada's opioid overdose epidemic, three separate laws were passed between 2015 and 2019. Provisions of the law are provided in Table 1. No research to date has examined state opioid legislation, the subsequent opioid-related death rates, and categorically analyzed these opioid-related deaths by legal and illicit opioids. The purpose of this research is to document the resulting temporal trends in opioid-related death rates relative to trends in opioid prescription rates between 2015-2020 in Nevada, while analyzing the cause of death between legal and illicit opioids.

Table 1. Summaries of Nevada's three opioid legislative bills: SB 459, AB 474, and AB 239.

\begin{tabular}{|c|c|c|c|}
\hline Law & Effective year & New opioid restrictions or regulations & Amendments to previous opioid restrictions or regulations \\
\hline $\begin{array}{l}\text { SB } 459 \\
{[9]}\end{array}$ & 2015 & $\begin{array}{l}\text { 1. A medical practitioner must query the Prescription Drug } \\
\text { Monitoring Program (PDMP) prior to writing an initial } \\
\text { and prior to writing a }>7 \text { day controlled substance (CS) } \\
\text { Schedule II, III, or IV prescription. } \\
\text { 2. Practitioners must report patients suspected of misusing } \\
\text { CS to the Board of Pharmacy. } \\
\text { 3. Prescribing physicians must receive one continuing } \\
\text { education credit on the misuse or abuse of prescription } \\
\text { drugs for each licensure period. } \\
\text { 4. Expanded access to the opioid antagonist naloxone (aka } \\
\text { Narcan). }\end{array}$ & $\begin{array}{l}\text { Not applicable as this was Nevada's first opioid-directed } \\
\text { legislation. }\end{array}$ \\
\hline $\begin{array}{l}\mathrm{AB} 474 \\
{[10]}\end{array}$ & 2018 & $\begin{array}{l}\text { 1. A practitioner cannot prescribe a CS that another } \\
\text { practitioner has prescribed for the same ongoing treatment. } \\
\text { 2. A practitioner must make a good faith effort to obtain } \\
\text { prior medical history that is relevant to the source of the } \\
\text { patient's pain. } \\
\text { 3. For the initial treatment of acute pain, a practitioner can } \\
\text { only prescribe a CS for } \leq 14 \text { days, only } \leq 90 \text { morphine } \\
\text { milligram equivalent (MME) if opioid naive, and must } \\
\text { obtain informed consent. }\end{array}$ & $\begin{array}{l}\text { Prior to prescribing a CS, a practitioner must query and obtain } \\
\text { an informed decision from the PDMP by considering a list of } \\
16 \text { factors outlined in the bill [SB } 459, \text { Item } 1] \text {. }\end{array}$ \\
\hline $\begin{array}{l}\text { AB } 239 \\
{[11]}\end{array}$ & 2019 & $\begin{array}{l}\text { 1. The practitioner must document that he/she has obtained } \\
\text { verbal or written informed consent; and, if the consent is } \\
\text { written, this document must be included in the medical } \\
\text { record. } \\
\text { 2. Provides exceptions for hospice, palliative, cancer, and } \\
\text { sickle cell prescriptions. }\end{array}$ & $\begin{array}{l}\text { 1. If a practitioner determines it is medically necessary, he/she can } \\
\text { prescribe the same CS that another practitioner has prescribed } \\
\text { for the same ongoing treatment AND he/she can prescribe an } \\
\text { initial CS prescription for treatment of pain that is }>14 \text { day } \\
\text { supply and }>90 \mathrm{MME} \text { daily [AB } 474 \text {, Items } 1 \& 3 \text { ]. } \\
\text { 2. If the prescription is }>30 \text { days supply, then the practitioner } \\
\text { must document that he/she has made a good faith effort to } \\
\text { obtain prior medical history that is relevant to the source of } \\
\text { the patient's pain [AB } 474 \text {, Item } 2 \text { ]. }\end{array}$ \\
\hline
\end{tabular}

New regulations and restrictions and modifications to the previous legislation are listed, with key messages of each law in bold and key changes underlined.

\section{Methods}

Data for the period between June 2015 and May 2020 was requested from the Nevada Board of Pharmacy (opioid prescriptions), the Clark County Office of the Coroner/Medical Examiner (opioid deaths), and the Washoe County Regional Medical Examiner (opioid deaths; January 2016 - February 2020 were made available). Clark County and Washoe County were home to approximately 2,738,234 (89\% of the Nevada's population) [12] in 2019.

Opioid-related deaths were placed in one of three categories: prescription opioids, heroin, or fentanyl. Five eras were identified relative to regulatory climate: before SB 459
(Era 1), after SB 459 but before AB 474 (Era 2), after AB 474 but before AB 239 (Era 3), after AB 239 but before COVID-19 Stay at Home order in Nevada (Era 4), and after the COVID-19 Stay at Home order (Era 5). To test for the possibility of different patterns in prescription rates and deaths in Clark County and Washoe County, a two-way analysis of variance (ANOVA) was initially fit, which included county, era, and the county by era interaction. Clark and Washoe counties had statistically similar trends, so the two counties were combined and one-way ANOVAs were used to compare monthly opioid related deaths and prescription rates during each era. Tukey post-hoc tests were used to look at differences between pairs of eras. Graphical 
representations of trends over time by county were also utilized, since deaths would be expected to lag prescription rates by an undetermined period of time.

\section{Results}

The overall rate of opioid prescriptions has trended downwards since 2015 (Figure 1). SB 459 had no statistically significant impact on opioid prescriptions, whereas there was a $27.4 \%$ drop in prescriptions after $\mathrm{AB} 474$, and an additional $14.0 \%$ drop after AB 239. Trends suggest that the drop after AB 239 was associated with the steady decline in opioid prescriptions set in motion by $\mathrm{AB} 474$. Prescribing rates were the same between counties $(F=3.4, P=0.068, \mathrm{df}=81)$, and changes in prescribing rates relative to the era did not vary by county after $\mathrm{AB} 474(F=0.1, P=0.762, \mathrm{df}=81)$ or $\mathrm{AB} 239$ $(F=0.1, P=0.701, \mathrm{df}=48)$.

The overall rate of opioid related deaths from 2015 through 2020 did not significantly change until the COVID19 pandemic caused Nevada Governor Sisolak to issue Stay at Home orders on March 17, 2020 [13] (Figure 2). However, deaths shifted from prescription opioids, which decreased $57.4 \%$ (6.9 fewer deaths per month) between eras 2 and 5 (ANOVA: $F=11.3, P<0.001 ; \mathrm{df}=4,55)$ to fentanyl, which increased 568.3\% (adding 13.9 deaths per month) between eras 2 and $5(F=22.7, P<0.001, \mathrm{df}=4,55)$, while rates of heroin-related deaths increased $41 \%$ (2.6 additional deaths per month; $F=2.7, P=0.037, \mathrm{df}=4,55$; Figure 2).

From 2015 to present, opioid deaths increased while opioid prescriptions declined (Figure 1). Deaths from opioid prescriptions fell in concert with the number of prescriptions (Spearman correlation $\left(r_{s}\right)=0.67$; Figure 1 ). The rise in overall deaths was due to illicit opioids, which were negatively correlated with opioid prescriptions (heroin: $r_{s}=-$ 0.33; fentanyl: $r_{s}=-0.72$; Figure 1).

\section{Clark County}
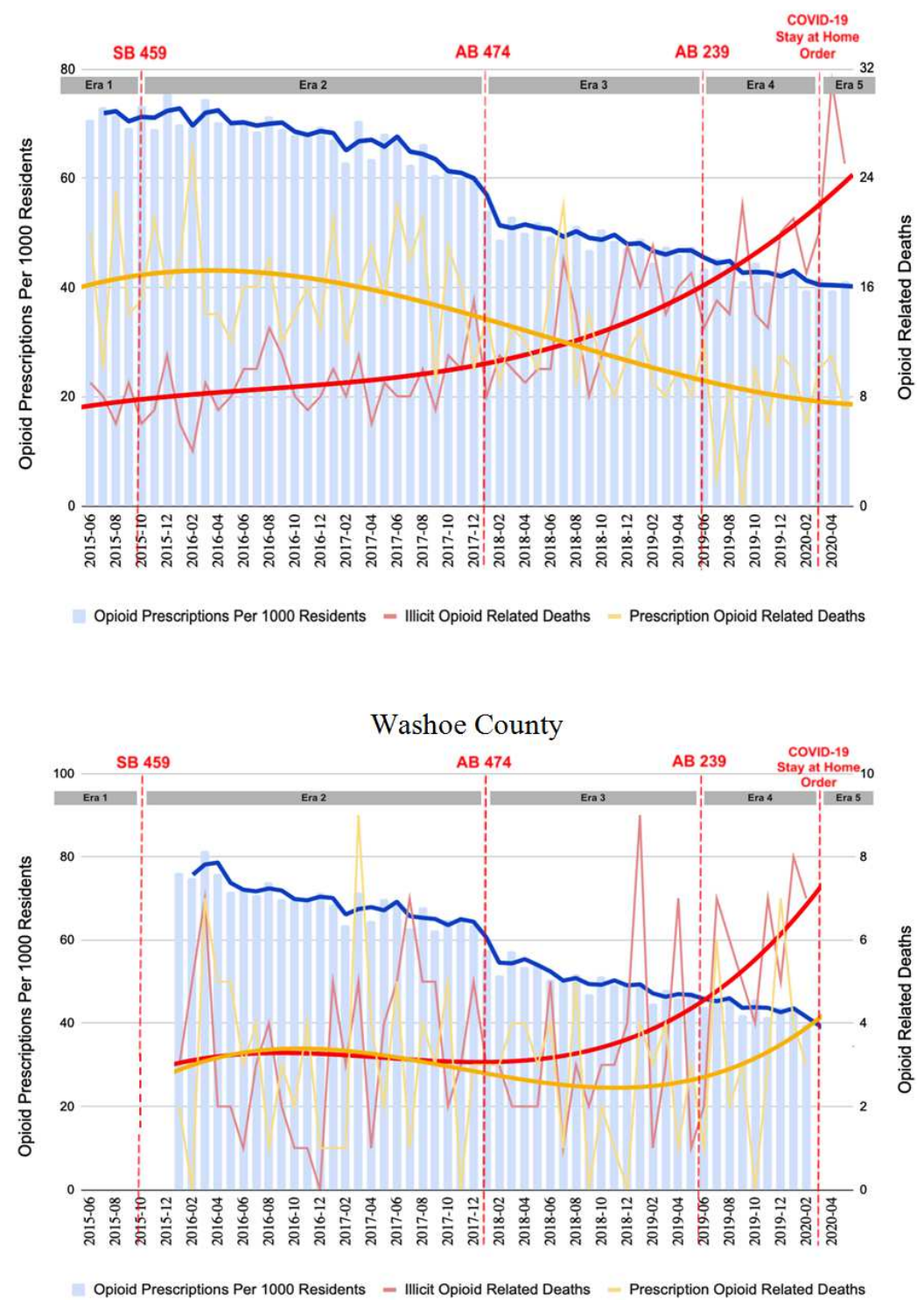

Figure 1. Opioid Prescriptions versus Illicit Opioid Related Deaths and Prescription Opioid Related Deaths in Clark and Washoe County. 
Monthly prescriptions per 1,000 residents were fitted with a moving average trend line with a window of two months (descending blue line). The prescription (yellow line) and illicit (red line) opioid-related death data were fitted with a cubic (3rd degree) polynomial trend line.

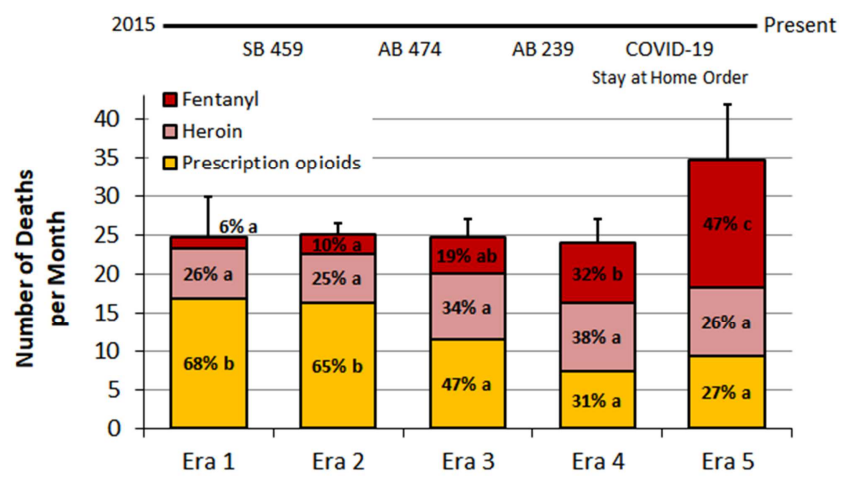

Figure 2. Mean Rates of Opioid-Related Deaths per Month in Clark County.

Error bars are $95 \%$ confidence intervals for total number of opioid-related deaths) per era. Prescription opioids, heroin, and fentanyl are reported separately. Percentages represent are based on all opioid deaths per era. Letters after the percentages show statistical differences among eras in monthly death rates for each sub-category of opioid based. Overall death rates did not vary by era, except that deaths in Era 5 were significantly higher than in Eras 1-4.

\section{Discussion}

The goal of Nevada's three opioid prescription bills was to limit the number of Nevadans dying from opioid overdose. The legislation was effective in reducing opioid prescriptions because deaths from legal opioids correspondingly fell. However, deaths from illicit opioids increased to produce a higher opioid death rate than before the legislation was enacted. There are several potential and possibly overlapping reasons for the large increase in illicit opioid deaths, including switching from legal to illegal sources of opioids, the larger societal context of illicit opioid availability, and emergencies such as the COVID-19 pandemic. The unintended consequences of the legislation are also worthy of consideration.

Nevadans who use illicit opioids may or may not have become addicted based on a prescription opioid. One justification for reducing opioid prescriptions is that an opioid prescription is a gateway for illegal opioids. Nevadans become addicted through a legal or partially-legal channel and then transition to an illicit opioid once they lose access to a prescription opioid. One study suggests that the legal opioid prescription to illicit opioid pathway describes $75 \%$ of current illicit opioid users [14]. It is unknown if the percent of those addicted through a prescription remained constant during the study period.

If most Nevadans are initially addicted to opioids through a prescription, reducing the number of opioid prescriptions should reduce deaths from both legal and illicit opioids. However, legislation resulting in fewer opioid prescriptions failed to reduce illicit opioid deaths in this study and in Kentucky [15]. To date, no state other than Kentucky has similarly analyzed their opioid legislation and reported deaths from legal and illicit opioids separately. Therefore, it is difficult to compare Nevada's opioid laws to other states' legislative efforts. It is our hope that this study serves as an impetus for other states to perform similar research on the effectiveness of their opioid prescribing laws as it relates to both legal and illicit opioid-related deaths. Understanding the effect of opioid prescribing rates on opioid deaths is difficult because deaths, particularly those from illicit opioids, are a lagging indicator that occur an unspecified period of time after the initial prescription. For a lag time 0.5 to 3 years, this study indicates that improvements to the legal opioid prescription to illicit opioid death pipeline were either minimal in size or they were masked by other factors.

Nevadans can more easily obtain fentanyl in 2020 than was possible in 2014. According to the US Drug Enforcement Administration's, the US Customs and Border Protection reported a $164 \%$ increase in fentanyl flowing into the country from both Mexico and China from 2014 to 2018 [16]. The increased availability of illicit opioids occurred at the same time as the enactment of well-intentioned laws aimed at constraining prescribers, so the trends being studied are only partially due to legislation and prescription opioids. There is a strong possibility that the laws have escalated illicit opioid deaths, as law-abiding Nevadans are driven to obtain easily available, lethal, illegal, and unregulated opioids to relieve their pain.

The trends documented in this study suggest that AB 474 initially shifted opioid prescription rates downward and reduced death rates, both of which continued to drop at a steady rate per month thereafter. There was no perceptible impact of SB 459 or AB 239 in causing additional drops or shifting the ongoing trends in opioid prescribing rates and deaths. Further examination is required to understand what provision (s) of $\mathrm{AB} 474$ that affected prescription rates and death rates. The two best candidates were that a practitioner must make a good faith effort to obtain prior medical history that is relevant to the source of the patient's pain, or the limits on the amount of opioids prescribed for initial treatment of opioid naive patients.

All legislation must balance achieving desired outcomes and limiting unintended consequences. Anecdotally, Nevada health care providers have responded to the opioid laws in ways that may be considered less than optimal, particularly for patients with emergencies or complicating factors. It may be desirable to revisit and repeal laws that have not been effective or that have had unanticipated impacts on routine medical care. For example, the standard treatment for a patient with sickle cell disease having an acute vasoocclusive crisis is to provide fluids, administer in-office 
opioids, and immediately write the patient an opioid prescription to control pain. The lengthy stipulations (e.g., considering the list of 16 factors during a PDMP query) specified by Nevada law prior to writing an opioid prescription are not practical during an emergency situation like a vaso-occlusive crisis. The impracticality of the opioid laws has led providers to shy away from prescribing effective and vital opioid pain management. Instead, some providers have chosen to advise their patients to take acetaminophen and NSAID medications, which carry a risk of liver and kidney toxicity and may not provide sufficient pain control. Patients who have their pain treated suboptimally can suffer needlessly without someone to advocate for them. The number of patients who experience such a scenario is challenging to enumerate, but the possibility must be on policymakers' minds when enacting legislation.

Beyond the legislative environment, society-wide external stressors, such as COVID-19 Stay at Home order, have been a strong contributor to the increase in illicit opioid deaths. If the patterns are consistent as more data becomes available, reasons for the increase in illicit opioid deaths during the pandemic should be investigated.

This study has limitations. The analysis excluded rural parts of Nevada, which may have responded differently to the legislation. Sample sizes were smaller and the date range more limited in Washoe County, so trends were less certain. Uncertainties about conversion rates from prescription opioids to illegal opioids over time limit the interpretation of the. Finally, more months of data are needed to corroborate the findings regarding the effects of the COVID-19 Stay at Home order on fentanyl death rates in Nevada.

\section{Conclusion}

AB 474 was effective in reducing the number of opioid prescriptions, and deaths from legal opioids consequently dropped by twofold. However, the total number of opioid deaths rose, due to an increase in deaths from illicit opioids, particularly fentanyl. Consequently, more Nevadans are dying after the opioid regulations were enacted than were dying before. The ideal policy for opioid control is one that fosters appropriate pain management and protects the greatest number of people from poor outcomes, including addiction, unrelenting pain, and desperation leading them to seek illicit pain control.

The members of the Nevada Legislature have it within their power to take concrete, actionable steps to reduce the total number of Nevadans dying from opioids and at the same time give physicians more latitude to address their patient's legitimate pain. Our recommendations are as follows:

(1) Use guidelines regarding opioid prescribing issued by agencies which are medically oriented, such as the CDC and the Federation of State Medical Boards. Such guidelines are representative of the best scientific evidence available. Existing rules that do not meet this standard (e.g., checking off 16 factors when perusing the PDMP) should be rescinded. The strict use of guidelines issued by medically oriented agencies has the additional advantage that changes to guidelines based on updated scientific information do not require updates to the law.

(2) Disciplining physicians who do not adhere to the guidelines should be done in a two-tier system: education, then sanctions.

(3) Enforcing the rules regarding opioid prescriptions should be assigned to an entity which fully understands a providers' scope of practice. For example, the Nevada State Board of Medical Examiner and the Nevada State Board of Osteopathic Medicine would be appropriate entities to sanction physicians.

These three provisions will allow providers to confidently prescribe appropriate pain management for their patients without fear of sanction from another licensing board's misunderstandings, allow providers to humanely manage their patients' legitimate pain, and reverse the laws' unintended consequences of patients being forced to seek out illicit opioids to control their pain and inadvertently dying in the process.

\section{Acknowledgements}

We would like to thank John Fudenberg and Nicole Charlton of Clark County Coroner-Medical Examiner, Justin Norton of Washoe County Regional Medical Examiner, and Darla Zarley and Jennifer L. Thompson of the Nevada State Board of Pharmacy for their data sharing efforts.

\section{References}

[1] Stefano, G. B., Pilonis, N., Ptacek, R., \& Kream, R. M. (2017). Reciprocal evolution of opiate science from medical and cultural perspectives. Medical Science Monitor: International Medical Journal of Experimental and Clinical Research, 23, 2890-2896. https://doi.org/10.12659/msm.905167.

[2] Schmitz, R. (1985). Friedrich Wilhelm Sertürner and the discovery of morphine. Pharmacy in History, 27 (2), 61-74.

[3] Centers for Disease Control and Prevention (2020). Opioid overdose: Understanding the epidemic. Retrieved from: https://www.cdc.gov/drugoverdose/epidemic/index.html.

[4] Centers for Disease Control and Prevention (2018). Opioid basics. Retrieved from https://www.cdc.gov/drugoverdose/opioids/index.html.

[5] De Leon, J. (2018). Associations between opioid-related hospitalizations and intravenous drug users (Order No. 13423851). Available from ProQuest One Academic. (2210170970). Retrieved from https://www.proquest.com/dissertations-theses/associationsbetween-opioid-related/docview/2210170970/se2? accountid $=28843$.

[6] Kim P. C., Yoo J. W., Cochran C. R., Park S. M., Chun S., Lee Y. J., \& Shen J. J (2019). Trends and associated factors of use of opioid, heroin, and cannabis among patients for emergency department visits in Nevada: 2009-2017. Medicine (Baltimore). 98 (47): e17739. doi: 10.1097/MD.0000000000017739. 
[7] Nevada State Opioid Response (2021). Suspected Nevada drug overdose surveillance monthly report May 2021: Statewide report. Retrieved from: https://www.nvopioidresponse.org/publications-documents/.

[8] Paul ABM, Simms L, Mahesan AA, Belanger EC. Teens, Drugs, \& Vegas: Toxicological surveillance of illicit prescription and illegal drug abuse in adolescents (12-17 years) using post-mortem data in Clark County, Nevada from 2005 to 2015. Journal of Forensic and Legal Medicine, 58, 20-24. doi: 10.1016/j.jflm.2018.04.002.

[9] Nevada State Legislature (2015) Senate Bill (S. B.) 459. Retrieved from https://www.leg.state.nv.us/app/nelis/rel/78th2015/bill/2162/O verview.

[10] Nevada State Legislature (2017) Assembly Bill (A. B.) 474. Retrieved from https://www.leg.state.nv.us/App/NELIS/REL/79th2017/Bill/5 735/Overview.

[11] Nevada State Legislature (2019) Assembly Bill (A. B.) 239. Retrieved from https://www.leg.state.nv.us/App/NELIS/REL/80th2019/Bill/6 425/Overview.
[12] U. S. Census Bureau (2020). Nevada 2019 Population Estimates. Retrieved from: https://www.census.gov/searchresults.html?search Type $=$ web $\& \operatorname{cssp}=$ SERP $\& q=$ nevada $\% 20$ po pulation.

[13] Nevada Health Response (2020). Nevada Health Response COVID-19 Risk Mitigation Initiative [press release]. Retrieved from: http://gov.nv.gov/News/Emergency_Orders/2020/2020-0312_-_COVID-19_Declaration_of_Emergency/.

[14] Cicero T. J., Ellis M. S., Surratt H. L., \& Kurtz S. P. (2014). The changing face of heroin use in the United States: A retrospective analysis of the past 50 years. JAMA Psychiatry, 71 (7), 821-826. doi: 10.1001/jamapsychiatry.2014.366.

[15] Victor, G. A., Walker, R., Cole, J., \& Logan, T. K (2017). Opioid analgesics and heroin: Examining drug misuse trends among a sample of drug treatment clients in Kentucky. International Journal of Drug Policy, 46, 1-6. doi: 10.1016/j.drugpo.2017.01.008.

[16] Department of Justice Drug Enforcement Agency (2019). National threat assessment. Retrieved from: https://www.dea.gov/sites/default/files/2020-01/2019-NDTAfinal-01-14-2020_Low_Web-DIR-007-20_2019.pdf. 